\title{
Performance Analysis of AODV, DSR and DSDV in MANETS
}

\author{
Nilesh Chandra \\ Research Scholar \\ Kamla Nehru Institute of Technology \\ India
}

\begin{abstract}
A mobile ad hoc network (MANET) is a progressive selfgestalt, infrastructure-less network of mobile node or static node connected without any wires. Each node in a MANET is independent to move in any direction and its link to another node very fast and forward packet to other node which is not related to its own use. So we can say a node can be a router. Routing is the primary challenge in MANET due to frequent and unpredictable changes occur in network topology and absence of any centralized control[1][2]. There are several routing protocol like DSDV, AODV and DSR.

This paper gives the overview of these routing protocols as well as the feature and function of these routing protocol and make their comparative analysis in order to measure the performance of the network. The main content of this paper is to compare the performance of above three mention routing protocols on the basis of various parameters such as throughput, delay and packet delivery ratio. Make the observations about how the performance of these routing protocols can be improved.
\end{abstract}

\section{Keywords}

MANET, AODV, DSDV and DSR

\section{INTRODUCTION}

Over the past year, researchers have made various researches in the field of mobile computing especially MANETs. A mobile ad hoc network (MANET) is a continuously self-

\author{
Sarita Soni \\ Research Scholar \\ Kamla Nehru Institute of Technology \\ India
}

\begin{abstract}
gestalt, without infrastructure support network of mobile devices connected without wires. Ad hoc is Latin word and means "for specific purpose"[1].
\end{abstract}

Each node in a MANET is independent to move in any direction, and will change its links to other devices frequently. Each device must forward packet which is not related to its own use, and therefore be a router. The primary challenge in building a MANET is set up each device to successively manage the information required to accurately route traffic. Such networks may operate by themselves or may be connected to the larger Internet. They may contain one or multiple and different hop between nodes. This results in a highly dynamic, self determining topology.

MANETs are a kind of Wireless ad hoc network that usually has a routable networking environment on top of a Link Layer ad hoc network. MANETs consist of a peer-to-peer, self-forming, self-healing network in contrast to a mesh network has a central controller.

There are many routing protocols present, this paper focus only on AODV, DSR and DSDV for comparisons of performance due to its closeness among all other routing protocols. These routing protocols are compare based on the important metrical such as control overhead, throughput, packet delivery ratio and average end-to-end delay and is presented with the simulation results obtained by NS-2 simulator.

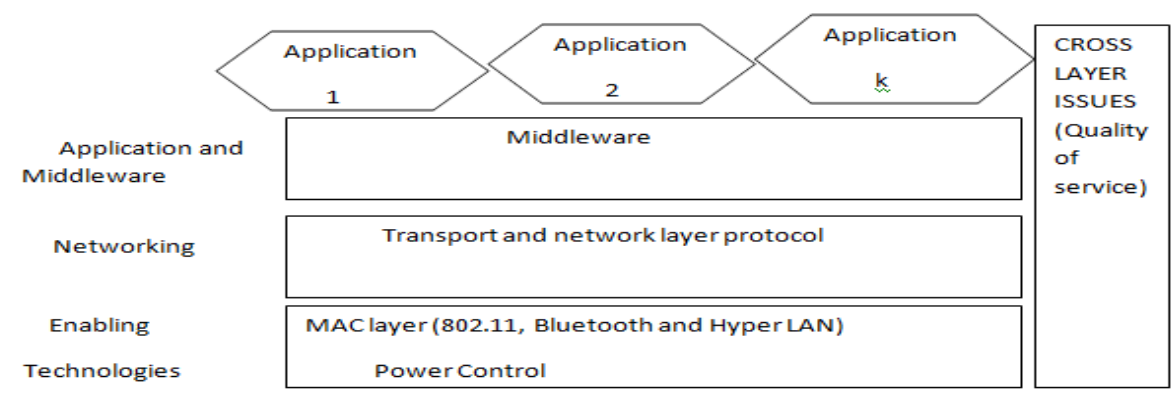

Figure 1. Structure of MANET 


\section{CHALLENGES FACED BY THE MANET}

MANET is very different network environment from the infrastructure based network. MANET has to faced various threat in order to achieve best quality of service for basic network.

Some of these threats are as follows.

- Unicast and multicast routing

- Dynamically change of tropology

- $\quad$ Speed and network overhead

- $\quad$ Limited Power supply and bandwidth

- $\quad$ Secure routing

- $\quad$ Energy efficient routing

\begin{tabular}{|c|c|}
\hline Application Layer & - Security \\
\hline Transport Layer & $\begin{array}{l}\text { - Quallity of Service } \\
\text { - Secure Routing }\end{array}$ \\
\hline Network Layer & - Unicastand Multicast \\
\hline Data Link Layer & - Speed and Network Overhead \\
\hline Physical Layer & - Power Control \\
\hline
\end{tabular}

Figure 2. Challenges are faced at the different layer of MANET's

\section{MOBILE AD HOC NETWORK ROUTING PROTOCOL}

MANET Routing Protocol van be mainly classified in three types: Proactive(Table -driven), Reactive(On Demand ) and Hybrid protocol.[3]

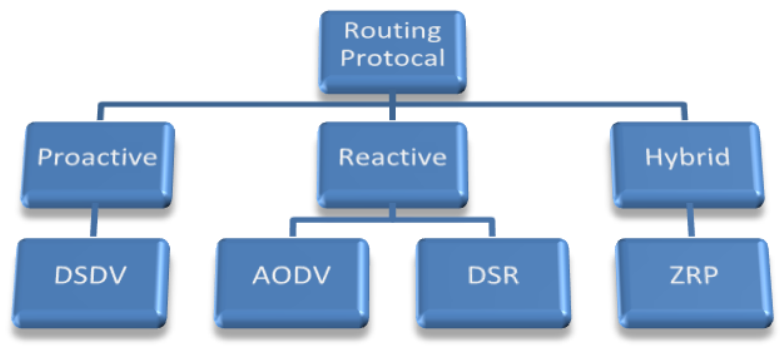

\subsection{Destination Sequence Distance Vector (DSDV)}

DSDV is the table driven, hop by hop distance vector routing protocol. In DSDV each node need to broadcast their routing table periodically based on BELLMAN_FORD routing algorithm. The routing table of each node contain some information : "NEXT_HOP" for each reachable destination node , Number of hop to reach destination and Sequence number assign by destination node. The sequence number used to avoid loop formation. Each node transmit their routing table to their immediate neighbours. A node may transmit routing table if any changes has occurred. So update is both Time_ Driven and Event__Driven.[4]

There are two method to reduce the information carried in each broadcast message.

Full Dump

It carries all the routing information.

\section{Incremental Carry}

The message contain only update information since last full dump.

\section{ADVANTAGE}

It is the early algorithm available and efficient protocol for small number of node and creating small size of Ad hoc network.

\section{DISADVANTAGE}

In DSDV regular update require while network is idle. That use up battery power and Bandwidth Whenever topology changes need new Sequence number. Thus it is not suitable for highly dynamic network

\subsection{AD HOC ON DEMAND DISTANCE VECTOR (AODV):-}

AODV routing protocol is the combination of DSDV and DRS routing protocol. The main aim of AODV routing protocol is to provide safe and reliable route and transmission.

When a node want to transfer a data to other node then source node initiate the route discovery process. The source node flood the RREQ (ROUTE_REQUEST) packet in the network. The intermediate node save the information: source, destination and node from which they received RREQ packet. When RREQ packet reach to destination node then that destination node send RREP (ROUTE_REPLY) packet through the reverse path set by RREQ.

In AODV routing protocol, the intermediate node delete all the store information after some time (Time out) for reducing overburdening. Whenever intermediate node or destination node move from the network then node initiate the RERR (ROUTE_ERROR) packet and send to source node, after receiving RERR packet source node reinitiate the route _discovery process.[5]

In AODV routing protocol neighbourhood information update by periodic broadcast. There are two method for route maintenance.

\section{ACK message- used in MAC layer \\ HELLO message- used in NETWORK layer}

\section{ADVANTAGE}

Route to destination node create on demand. For latest destination's route destination sequence number is use .Connection establishment delay is lower.

\section{DISADVANTAGE}

Inconsistent route can be leads by intermediate node. Multiple RREP packet generate for single RREQ packet.

\subsection{DYNAMIC SOURCE ROUTING (DSR)}

DSR is the one of the Reactive routing protocol which manage MANET without using periodic updated routing 
table. When a node need to transmit data to destination node then source node initiate route discovery process and flood RREQ packet over the network. RREQ packet consist the details of hop or intermediate node. When the packet reach to destination node or intermediate node that know route to destination then that node send RREP packet to source node through the reverse route.

One RREQ packet leads to multiple RREP response. So source node store all the response to cache and select one optimal path to start transmission. If any point of time any error occurred and source node received RERR packet then source node choose another optimal path from cache storage instead of reinitiate route discovery [6].

The main difference in AODV \& DSR :- Information store at intermediate node in AODV while in DSR, information store at source node.

\section{ADVANTAGE}

DSR does not need periodic update. DSR routing protocol is bandwidth saving.

\section{DISADVANTAGE}

DSR protocol is effective for less than 200 node. DSR does not repair broken link locally.

\section{SIMULATION AND ANALYSIS METHOD}

Network Simulator-2 is a open source software.NS-2 is used for analyzing and evaluating different MANET routing protocol and topology. Simulation is important tool for new technology.

Simulation help us to analyse and evaluate the performance and behaviour of network before implementing it in real life application.[7]

In this paper we consider some performance metric for evaluating different routing protocol.

\section{Packet delivery ratio (PDR)}

PDR define as the ratio of data packet received to total number of packet sent.

\section{Throughput}

Throughput define as the total number of packet transmitted successfully in per unit of time.

\section{Average end to end delay}

It is define as the average time taken by data packet to transmit from source to destination node. It include all other type of delay such as buffer, retransmission and interface queue.

\section{Control Overhead}

It is define as the ratio of control information sent to each node where data received.

\section{RESULT AND DISCUSSION}

Here, we compare the reliable performance of three routing protocol AODV,DSDV and DSR in same simulation environment. Simulation result based on 60 scenarios of these protocol. Performance metric are evaluated from trace file and AWK program.

The simulation result are shown using graph.

Graph 1. PDR Vs Number of Nodes(With Connection of 5)

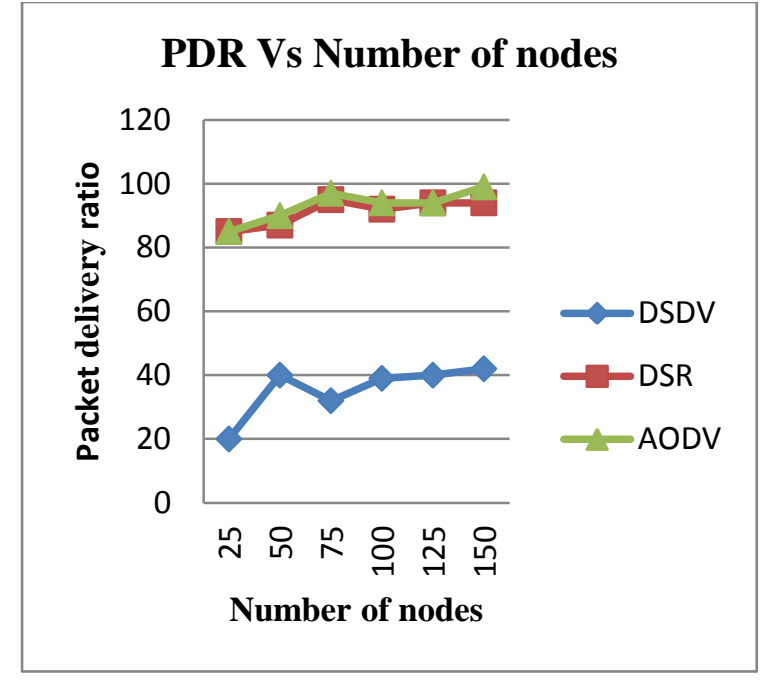

Graph 2.PDR Vs Number of Node(With Connection of 10)

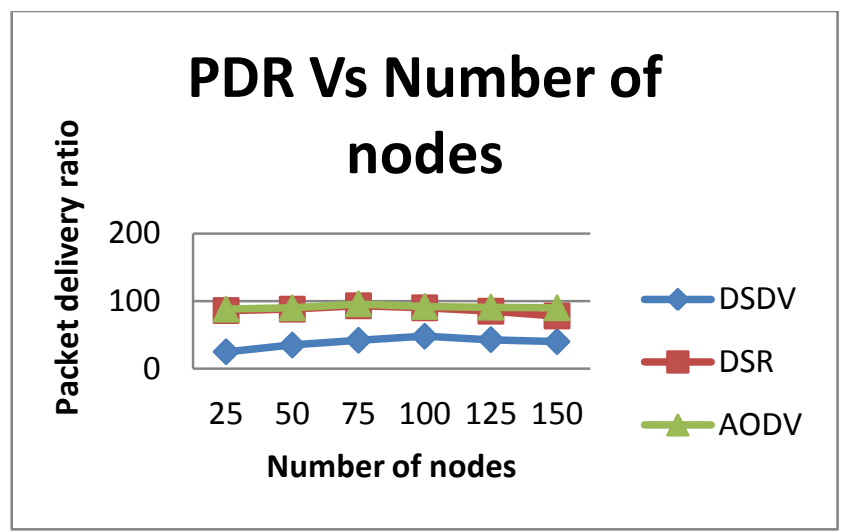

From Graph 1 we see that there is small advantage to AODV, when number of node linearly increased in network. Overall the Packet delivery Ratio (PDR) of AODV and DSR are higher than DSDV.

In Graph 2 we see that the PDR is much large in AODV than DSR in large mobile network. DSR performance is well in less number of node but it drastically decline with increase in number of node. Over all the performance of AODV is high than other routing protocol with respect to Packet Delivery Ratio.

Graph 3. Throughput Vs Number of Nodes

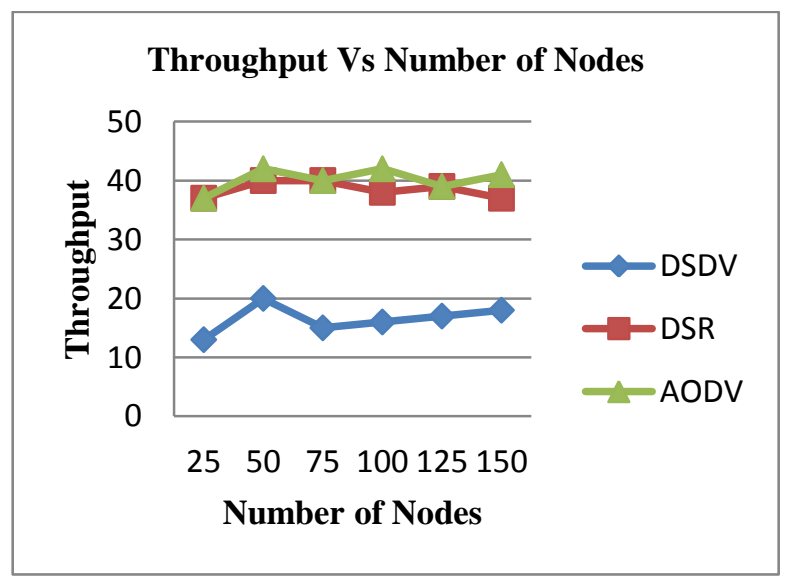


From the above graph we see that throughput of AODV is higher than other two routing protocol. Throughput of DSR is very similar to AODV but with increasing number of nodes in network throughput of DSR is decrease while throughput of AODV is increased with increase in number of nodes. The throughput of DSDV is much lower than all other routing protocol.

\section{Graph 4. Average end to end delay Vs Number of Node}

\section{Average end to end delay Vs Number of node}

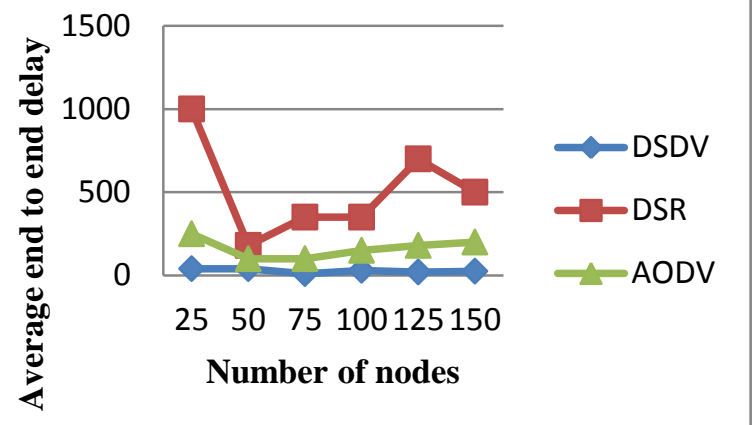

The performance of DSR is decrease with increase in number of node. Performance of AODV is slightly better than DSR. The performance of DSDV is constant as increase in number of nodes.

\section{Graph 5. Control Overhead Vs Number of Node}

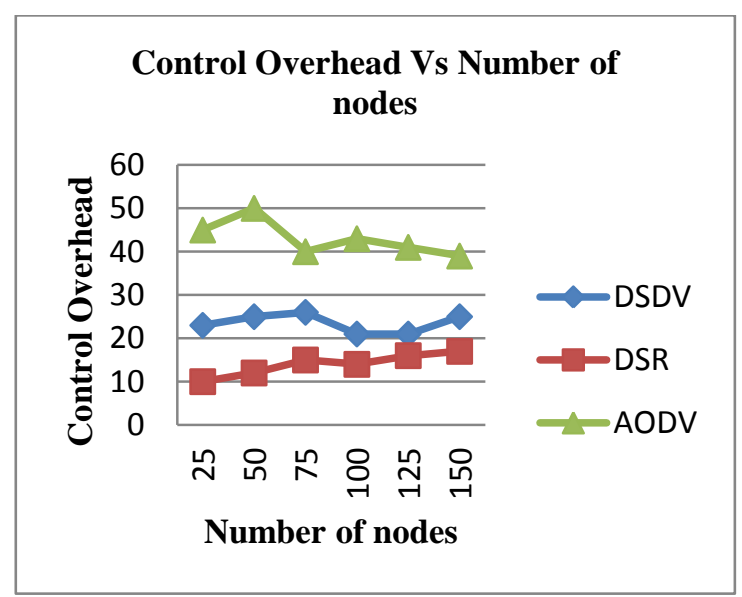

In AODV routing protocol, control overhead is increase with increase in number of node in network. Control overhead is highest in comparison to DSDV and DSR protocol. In DSR control overhead is increase with very small rate of change.

Table 1.Comparison of AODV, DSDV and DSR routing protocol based on different performance metrics

\begin{tabular}{|l|l|l|l|l|}
\hline & $\begin{array}{l}\text { Packet } \\
\text { Delivery } \\
\text { Ratio }\end{array}$ & $\begin{array}{l}\text { Through } \\
\text { put }\end{array}$ & $\begin{array}{l}\text { Average } \\
\text { end to } \\
\text { end delay }\end{array}$ & $\begin{array}{l}\text { Control } \\
\text { overhead }\end{array}$ \\
\hline $\begin{array}{l}\text { AOD } \\
\text { V }\end{array}$ & High & High & $\begin{array}{l}\text { Performa } \\
\text { nce } \\
\text { decrease }\end{array}$ & $\begin{array}{l}\text { Control } \\
\text { overhead } \\
\text { increase } \\
\text { with }\end{array}$ \\
\hline
\end{tabular}

\begin{tabular}{|l|l|l|l|l|}
\hline $\begin{array}{l}\text { DSD } \\
\text { V }\end{array}$ & Least & Least & $\begin{array}{l}\text { Least and } \\
\text { remain } \\
\text { constant }\end{array}$ & $\begin{array}{l}\text { Performa } \\
\text { nce varies } \\
\text { within } \\
\text { AODV } \\
\text { and DSR }\end{array}$ \\
\hline DSR & $\begin{array}{l}\text { Performa } \\
\text { nce well } \\
\text { when } \\
\text { node is } \\
\text { less }\end{array}$ & $\begin{array}{l}\text { Better } \\
\text { than } \\
\text { DSDV }\end{array}$ & $\begin{array}{l}\text { Decrease } \\
\text { when } \\
\text { node } \\
\text { density is } \\
\text { high }\end{array}$ & $\begin{array}{l}\text { Best as } \\
\text { compare } \\
\text { to DSDV } \\
\text { and } \\
\text { AODV }\end{array}$ \\
\hline
\end{tabular}

\section{CONCLUSION}

In this paper, we discuss the classification of routing protocol and performance metric. We evaluate the AODV, DSR and DSDV protocol based on throughput, Packet delivery ratio, Average end to end delay and control overhead performance metrics. We see AODV is better than other these routing protocol in terms of throughput and packet delivery ratio. While DSDV is better in terms of average end to end delay and DSR is better than these protocol in terms of control overhead. Overall analysis of these three routing protocol we can say that AODV is best routing protocol in MANET as compare to DSDV and DSR.

\section{REFERENCES}

[1] S.Mohapatra, P.Kanungo "Performance Analysis of AODV, DSDV, OLSR and DSR routing protocol using NS2 Simulator".

[2] V.Rajeshkumar, P.Sivakumar"Comparative study of AODV,DSDV and DSR routing protocol in MANET using NS2 Simulator".

[3] Xiaoyan Hong, Kaixin $\mathrm{Xu}$, and Mario Gerla. Scalable routing protocols for mobile ad hoc networks. 2002.

[4] Charles E. Perkins and Pravin Bhagwat, "Highly Dynamic destination-sequenced distance-vector routing (DSDV) for mobile computers . 1994.

[5] Perkins C.E. and Royer E.M, Ad-hoc, "On-demand Distance Vector Routing", draft-ietf-manet aodv02.txt, 1998 .

[6] David B. Johnson, David A. Maltz "Dynamic Source Routing in Ad Hoc Wireless Networks, Mobile Computing, Thomasz Imielinski and Hank Korth (Editors) ,"Vol. 353, Chapter 5, pp. 153181,Kluwer Academic Publishers, 1996.

[7] Narendra Singh Yaday, R.P.Yadav," Performance Comparison and Analysis of Table-Driven and OnDemand Routing Protocols for Mobile Ad-hoc Networks," International Journal of Information and Communication Engineering, 2008.

[8] Jochen Schiller. Mobile Communications. Addison-Wesley, 2000.

[9] Talooki, Ziarati VNK "Performance Comparison of Routing Protocols for Mobile Ad-hoc Networks, APCC 2005 pp 1-5 